\title{
O CRITÉRIO DE CIENTIFICIDADE POR MEIO DAS VIRTUDES
}

\author{
THE CRITERION OF SCIENTIFIC THROUGH THE VIRTUES
}

Adilson Koslowski*

\section{RESUMO}

O problema da demarcação é uma das clássicas questões em filosofia da ciência. Ele não teve muita atenção nas últimas décadas entre os filósofos da ciência comparada àquela recebida no início do século XX, contudo continua sendo importante. Pensamos existirem várias formas de buscar uma solução ao desafio. Apresentaremos uma proposta que tem suas origens na filosofia da ciência de Thomas Kuhn (1973). A escolha de teorias é baseada nas virtudes cognitivas e pragmáticas das teorias.

PALAVRAS-CHAVE: O problema da demarcação. Virtudes. Filosofia da ciência. Thomas Kuhn.

\section{ABSTRACT}

The problem of demarcation is one of the classic questions in philosophy of science. It has not had much attention in recent decades among philosophers of science compared to that received in the early twentieth century, yet still important. We think there are several ways to find a solution to the challenge. We will present a proposal which has its origins in the philosophy of science Thomas Kuhn (1973).

KEY WORDS: The problem of demarcation. Virtues. Philosophy of science. Thomas S. Kuhn.

\footnotetext{
${ }^{*}$ Professor de Filosofia na Universidade Federal do Sergipe/DFL. E-mail: adilsonkoslowski@ yahoo.com.br.
} 


\section{INTRODUÇÃO}

Nosso objetivo neste texto é sustentar a abordagem que remonta a Thomas Kuhn em seu ensaio Objetividade, juízo de valor e escolha teórica de 1973, dez anos após A estrutura das revoluções científicas $(1962)^{1}$, presente posteriormente em seu livro Tensão Essencial, de 1977. Pretendemos estabelecer algumas virtudes que possam nos orientar na decisão de ser uma teoria científica ou não. Semelhante ao médico que diagnostica seu paciente por meio de certos sintomas, mutatis mutandis, por meio das virtudes nós podemos estabelecer se uma teoria é científica ou não.

Não acreditamos que uma teoria geral possa dirimir todos os problemas quando nos deparamos com alguma visão que se supõe científica. Dado o fracasso de uma solução simples ao problema, existe vaguidade nos conceitos de ciência e não ciência que fazem com que abandonemos uma solução estabelecida em algum tipo de algoritmo. A proposta é proporcionar uma solução geral e não nos livrar imediatamente das controvérsias se uma dada teoria é ou não científica; porém, estabelece critérios gerais - as virtudes - que podem nos orientar no discernimento a respeito da cientificidade ou não de uma teoria.

\section{O PROBLEMA DA DEMARCAÇÃO: O QUE É E SUAS TRÊS FASES}

Os filósofos da ciência frequentemente discutem a natureza da ciência no chamado problema da demarcação. A saber, estabelecer um conjunto de propriedades ou características da ciência que a distingam de outras abordagens como a religiosa, a metafísica e, principalmente, a pseudociência. Em especial, a pseudociência sustenta teorias que se supõem científicas. Ultimamente, temos notado que a discussão da demarcação, no âmbito da filosofia da ciência, se centra no problema de distinguir entre ciência e pseudociência. Problemas como a distinção entre filosofia e ciência ou, mais especificamente, metafísica e ciência são tratados na metafilosofia, na metaontologia e não mais diretamente no problema da demarcação (PIGLIUCCI; BOUDRY, 2013).

O problema da demarcação foi tema central a partir dos anos 20 do século passado entre os positivistas lógicos e racionalistas críticos, perdendo infelizmente muito de sua

\footnotetext{
${ }^{1}$ Nesse livro e em outros Kuhn defende o critério de resolução de problemas como distinção entre ciência e pseudociência. Para Kuhn, a astrologia não é ciência e nunca foi, pois não tem como objetivo a busca de solução de quebra-cabeças, típico da atividade da ciência normal. Popper (1974), não obstante, sustenta que a astrologia tem seus puzzles, e esse não seria um critério adequado.
} 
importância entre os filósofos da ciência de nossos dias ${ }^{2}$. Segundo o filósofo húngaro Imre Lakatos (1980, p. 01): “A demarcação entre ciência e pseudociência não é um problema de filosofia de poltrona: é de vital relevância política e social." Lakatos tem razão. O critério de demarcação afeta o currículo na Escola e na Universidade, levando à questão sobre o que iremos ensinar. Afeta as políticas e agências de financiamento de pesquisa: para que instituição ou grupo de pesquisa devem ser distribuídos os recursos? Nos tribunais: que procedimentos são dignos de confiança para justificar certas sentenças? Nas universidades: que tipo de evento pode ser feito e fomentado nos campi das universidades? Na saúde: quais medicamentos e procedimentos adotar?

Esse assunto gera disputas calorosas. Há quem defenda que o marxismo, a psicanálise $^{3}$, a economia clássica, o criacionismo, a parapsicologia, a homeopatia, a astrologia, a teoria das supercordas sejam pseudociências. Contudo, existem defensores zelosos para todas essas alegadas ciências. Os casos mais beligerantes, em nossa opinião, são o ensino do criacionismo nas escolas (principalmente nos EUA) e a utilização de medicamentos e procedimentos como a homeopatia e a acupuntura na medicina.

Observando a história do problema, distinguimos, grosso modo, três momentos. O primeiro tem seu início na década de 20 e vai até a década de 60. Esse período é marcado pelas reflexões do positivismo lógico e do racionalismo crítico. É um período de otimismo exagerado acerca da possibilidade de estabelecer uma resposta ao problema da demarcação. Acreditam os filósofos desse período que podemos, a partir de um princípio único, resolver vários problemas em filosofia da ciência e igualmente o problema da demarcação.

No segundo momento, a confiança na possibilidade de estabelecer critérios de distinção entre ciência e não ciência desaparece, e somos levados ao outro extremo, o pessimismo da década de 60, que se expressa em obras da chamada "nova filosofia da ciência", hoje não tão nova, cujos membros principais são Thomas S. Kuhn, com a obra Estrutura das revoluções científicas de 1962, e Contra o método, de Paul Feyerabend, de 1975. A nova filosofia da ciência influenciou perspectivas altamente críticas da ciência moderna como alguns teóricos da sociologia do conhecimento científico (programa forte) que negam qualquer critério objetivo de distinção epistêmica ou racional entre ciência e quaisquer discursos, como é expresso na obra de Bruno Latour e Steve Woolgar intitulada Vida em

\footnotetext{
${ }^{2}$ Para uma visão geral do problema, ver o verbete da Stanford Encyclopedia of philosophy "Pseudo-science and Science" de Sven Ove Hansson (2015).

${ }^{3}$ O caso da psicanálise é bastante controverso. Ver as críticas em Pinckney (1970), Mello (1967), Perelson (2005), Onfray, (2011), Santamaría e Fumero, (2008). Para uma defesa, ver Roudinesco (2011).
} 
laboratório: a fabricação de fatos científicos, de 1997. Outro exemplo vem do polêmico filósofo e físico Paul Feyerabend (2007, 2011), que defendeu um critério anarquista, a saber, que não há critério ou critérios que distingam a ciência de outras teorias ou mesmo do mito. De acordo com Feyerabend, o prestígio epistêmico da ciência advém de seus compromissos e benefícios políticos; o que precisamos é separar a ciência do Estado, assim como separamos há algum tempo a Igreja do Estado; as pessoas devem ser livres para escolher as teorias que desejam e não estar submetidas às decisões arbitrárias da comunidade científica e dos governos.

No terceiro momento, em nossos dias, existem tentativas que desejam estabelecer critérios entre os excessos de otimismo e pessimismo relativista. Nossa proposta se enquadra nessa tentativa.

Como já dissemos anteriormente, existem várias estratégias ou modelos para resolver o problema da demarcação. Para exemplificar, apresento três estratégias. A primeira estratégia é estabelecer uma definição de ciência e, consequentemente, estabelecer critérios de distinção a partir da definição ou da natureza da ciência. Selecionamos dois exemplos que são as propostas dos filósofos Michel Ghins e Mario Bunge. Uma segunda estratégia é sustentar a existência de um método científico que deve ser respeitado pelos cientistas para que o seu produto seja uma teoria ou modelo científico. Para essa estratégia recorremos novamente a Mário Bunge ${ }^{4}$. E, por fim, nossa proposta é estabelecer uma lista de virtudes teóricas e pragmáticas que nos ajudem a distinguir a ciência da pseudociência.

Mas, antes de apresentar essas três estratégias, vejamos algumas propostas que não foram bem-sucedidas na história da filosofia da ciência como solução ao problema da demarcação. Tudo o que é dito nesta pequena reconstrução histórica (incompleta) está espalhado em vários escritos sobre o assunto ${ }^{5}$. Contudo, vale apenas relembrar principalmente as duas soluções fracassadas do positivismo e do racionalismo crítico.

Os positivistas lógicos concebiam a ciência como uma linguagem diferente das demais. Para eles, a ciência é um discurso significativo. Aliás, a ciência é o único discurso completamente significativo. Os enunciados científicos das ciências empíricas são sintéticos e empiricamente verificáveis. A saber, um conjunto finito de observações pode tornar o enunciado científico empírico verdadeiro. Os enunciados das ciências formais, por sua vez,

\footnotetext{
${ }^{4}$ Deixamos claro que Bunge é um dos críticos da possibilidade de demarcar a ciências apelando para um único critério.

${ }^{5}$ Informações desenvolvidas neste texto a respeito do problema da demarcação foram influenciadas e devem-se ao Filósofo Antonio Diéguez Lucena, apresentadas na Universidade de Málaga em 04 de abril de 2014.
} 
são apenas tautologias. Há pelo menos dois sérios problemas com esse critério de demarcação: a ciência sustenta leis universais, como a Lei da Gravitação, que não podem ser verificadas por um conjunto finito de observações. E segundo o problema de Hume, os raciocínios indutivos não são demonstrativos, mas apenas prováveis.

Outra solução dada pelos positivistas ao problema foi estabelecer o critério de confirmação, enfraquecendo o requisito para um enunciado ser significativo e, portanto, verdadeiro. Um enunciado empírico é confirmado apenas probabilisticamente. Contudo, esse critério tinha seus próprios defeitos, entre eles, a segunda lei da termodinâmica, que não é passível de confirmação. Além disso, não se conseguiu estabelecer um cálculo de probabilidades que confirmasse uma lei com o mínimo de justificação.

Para complicar, as pseudociências podem ser confirmadas - como, por exemplo, algumas predições da astrologia. Por fim, o critério da verificação ou da confirmação quando aplicado a si próprio mostra-se inconsistente, perfazendo a chamada falácia da autorreferência $^{6}$. Mario Bunge (1989, p. 402) sustenta que o princípio de verificação é uma tese falsa. Há conceitos significativos e não verificáveis, e, antes de qualquer experimento para verificar algo, devemos saber o significado do que será testado. "O significado precede o teste e não o contrário". Em suma, teste e significação são independentes.

Segundo o critério do falseacionismo, as hipóteses científicas diferem das hipóteses não científicas, pois as primeiras podem ser falseadas ou refutadas. Enquanto as hipóteses das pseudociências não podem ser falseadas. Todas as evidências confirmariam as pseudociências. Os pseudocientistas elaboram teses e buscam apenas as evidências que possam confirmá-las e não as expõem às que possam falsificá-las. Além dos mais, tratam de elaborar teorias que são resistentes a qualquer tipo de evidência contrária, são autoimunes. Karl Popper exemplifica essa estratégia da pseudociência em Conjeturas e Refutações (1972, p. 65) a respeito da psicanálise:

Certa vez, em 1919, informei-o [a Adler] de um caso que não me parecia ser particularmente adleriano, mas que ele não teve qualquer dificuldade em analisar nos termos da sua teoria do sentimento de inferioridade, embora nem mesmo tivesse visto a criança em questão. Ligeiramente chocado, perguntei como podia ter tanta certeza. "Porque já tive mil experiências desse tipo" - respondeu; ao que não pude deixar de retrucar: "Com este novo caso, o número passará então a mil e um..." O que queria dizer era que suas observações anteriores podiam não merecer muito mais

\footnotetext{
${ }^{6}$ Por exemplo, a tese (1) afirma: "Não há nenhuma proposição verdadeira". Se aplicarmos o critério da tese (1) a si mesma torna-a paradoxal. A tese (1) não resiste ao seu próprio critério. Assim, tese (2) "Só as frases que são verificáveis são significativas", novamente, se aplicarmos o critério da tese (2), ela própria não é significativa, pois não é verificável.
} 
certeza do que a última; que cada observação havia sido examinada à luz da experiência anterior, somando-se ao mesmo tempo às outras como confirmação adicional. Mas, perguntei a mim mesmo, que é que confirmava cada nova observação? Simplesmente o facto de que cada caso podia ser examinado à luz da teoria. Refleti, contudo, que isso significava muito pouco, pois todo e qualquer caso concebível pode ser examinado à luz da teoria de Freud e de Adler. Posso ilustrar esse ponto com dois exemplos muito diferentes de comportamento humano: o do homem que joga uma criança na água com a intenção de afogá-la e o de quem sacrifica sua vida na tentativa de salvar a criança. Ambos os casos podem ser explicados com igual facilidade, tanto em termos freudianos como adlerianos. Segundo Freud, o primeiro homem sofria de repressão (digamos, algum componente do seu complexo de Édipo) enquanto o segundo alcançara a sublimação. Segundo Adler, o primeiro sofria de sentimento de inferioridade (gerando, provavelmente, a necessidade de provar a si mesmo ser capaz de cometer um crime), e o mesmo havia acontecido com o segundo (cuja necessidade era provar a si mesmo ser capaz de salvar a criança). Não conseguia imaginar qualquer tipo de comportamento humano que ambas as teorias fossem incapazes de explicar. Era precisamente esse fato - elas serviam sempre e eram sempre confirmadas - que constituía o mais forte argumento em seu favor. Comecei a perceber aos poucos que essa força aparente era, na verdade, uma fraqueza.

As verdadeiras teorias científicas, segundo o falseacionismo, têm como destino serem falseadas. O que deve o cientista fazer é procurar refutar as teorias e não buscar verificá-las ou confirmá-las. As teorias científicas aceitas são aquelas resistentes à falsificação e consequentemente têm um alto grau de corroboração.

Igualmente esse critério tem vários problemas. Para refutar algo, temos que aceitar algo como básico (enunciados básicos); mas esses enunciados básicos também são falíveis; logo, não podemos refutar nada absolutamente, mas apenas relativamente à nossa base empírica. Os cientistas também defendem hipóteses ad hoc. Por exemplo, o caso do neutrino postulado por Wolfgang Pauli, em 1930, ilustrado por Kuhn na Estrutura das revoluções científicas $^{7}$. Além disso, não há nada que possa falsear uma lei como a segunda Lei de Newton $(\mathrm{F}=\mathrm{m} . \mathrm{a})$, ou o segundo princípio da termodinâmica. Ademais, podem-se refutar afirmações da pseudociência, como certas previsões astrológicas.

\section{PROPONDO UMA DEFINIÇÃO DE CIÊNCIA}

Uma estratégia para resolver o problema da demarcação é construir uma definição de ciência. Tendo posse de uma definição de ciência, teremos consequentemente um critério de demarcação. Contudo, houve grande ceticismo na possibilidade de estabelecer a essência da

\footnotetext{
${ }^{7}$ Não que os cientistas acreditassem nos neutrinos antes de serem confirmados por experimentos, o que aconteceu bem mais tarde de sua postulação no ano de 1953 pelo experimento de Cowan e Reines realizado nos Estados Unidos, mas tinham esperança de que a existência dos neutrinos fosse confirmada, pois manteria o princípio fundamental da conservação de energia intacto.
} 
ciência a partir da década de 60. Muitas definições foram contestadas, pois elas refletiam as posições filosóficas e normativas dos seus proponentes que eram rejeitadas por outras perspectivas. Há igualmente entre os filósofos ${ }^{8}$ influenciados pelo segundo Wittgenstein que negam a possibilidade de haver uma definição essencialista de ciência. Contudo, tal estratégia não eliminou a busca pelas definições, pois há filósofos que continuam propondo definições da ciência que possibilitariam resolver igualmente o problema da demarcação.

Uma proposta de definição encontra-se no livro Uma introdução à metafísica da natureza: representação, realismo e leis científicas, de 2013, do filósofo belga Michel Ghins. Sumariamente, sua definição de ciência estabelece que uma teoria científica é um conjunto de modelos e proposições satisfeitas (tornadas verdadeiras) por esses modelos. Algumas dessas proposições alcançam o status de leis. Essas proposições são explicativas, descrevem mecanismos causais, e os elementos das teorias maduras devem ser interpretados (frequentemente) de modo realista. Longe de evitar controvérsias, tais definições pressupõem elementos contestados por outros filósofos. No caso da definiç̧ão de Ghins, temos a noção de modelo que é controversa, a defesa de leis científicas é contestada por filósofos como Bas van Fraassen em Laws and Symmetry (1989), Ronald Giere em Science without Laws (1999) e Nancy Cartwright em How the Laws of Physics Lie (1983) e Nature's Capacities and their Measurements (1989). A noção de mecanismo causal interpretado de modo realista será rejeitada por filósofos empiristas. Essa definição parece pressupor o monismo metodológico e, portanto, sustentar a indiferença entre ciências naturais e humanas, o que não é aceito por todos.

Outra proposta de definição de ciência que oferece explicitamente uma solução ao problema da demarcação é a de Mario Bunge. A ciência básica factual (BUNGE, 1989, p. 2829) é constituída de dez elementos ${ }^{9}$. O elemento base é a comunidade de pesquisadores (CP) que é constituída de pessoas treinadas, com forte comunicação entre si e aberta a receber e treinar outros indivíduos interessados. A CP pertence a uma comunidade maior, a sociedade. A sociedade fomenta a $\mathrm{CP}$ ou pelo menos a tolera. $\mathrm{O}$ discurso da comunidade de pesquisadores se refere a entidades reais e não a imaginosas ou fantasmagóricas. A CP possui uma filosofia ontologicamente realista. O mundo é composto de entidades concretas que

\footnotetext{
${ }^{8}$ Por exemplo, Dupré (1993).

9 São eles: (1) a comunidade dos investigadores; (2) a sociedade que os apoia ou tolera; (3) o domínio ou universo de discurso; (4) a concepção geral ou filosofia da CP, (a) a epistemologia realista, (b) o ethos, (5) o fundo formal; (6) o fundo específico; (7) os problemas; (8) o fundo de conhecimento acumulado, (9) os objetivos, (10) a metódica.
} 
mudam por meio de leis e são independentes do pesquisador. Uma epistemologia de que podemos conhecer o mundo parcial e gradualmente, e um ethos que busca a verdade acima de outros valores como a utilidade, o poder, o dinheiro. Possui uma coleção de teorias lógicas e matemáticas atualizadas e uma base de dados, hipóteses e teorias atualizadas e razoavelmente confirmadas e corrigíveis, bem como métodos efetivos. Os problemas que a CP deseja resolver são sobre coisas reais. Há um cabedal de teorias e hipóteses e dados compatíveis com o depósito fornecido pela tradição da CP. O objetivo da CP é descobrir regularidades, sistematizar teorias e refinar métodos. Os métodos são conferíveis, analisáveis e justificáveis. A CP é contígua com outras comunidades em seu objeto de pesquisa tanto quanto em métodos e teorias que compartilha com outras comunidades de pesquisa. Os elementos da comunidade, com exceção da sociedade que a hospeda, modificam-se com o tempo.

Bunge (2006, p. 56) sustenta que uma atividade cognitiva (e, igualmente uma teoria que não satisfaça mesmo que aproximadamente todas as condições) não é científica. As atividades que satisfazem parcialmente são semicientíficas ou protocientíficas. E aqueles campos que não satisfazem, mas se consideram científicos, são de fato pseudocientíficos. Para Bunge o conceito de ciência é não absoluto, mas gradual. As disciplinas são mais ou menos científicas, desenvolvidas em maior ou menor grau, perspectiva que consideramos muito importante quando lidamos com o problema da demarcação. De acordo com Bunge, toda e qualquer solução do problema da demarcação deverá levar em conta essa gradação, pois é raro teorias científicas nascerem completamente maduras (isso se alguma delas for real e completamente madura).

De um modo mais sintético e direto, Bunge (2006, p. 58) resume seu critério de demarcação assim: "Uma hipótese ou teoria é científica se e somente se (a) for precisa; (b) for compatível com o grosso do conhecimento cientifico relevante, e (c) juntamente com hipóteses subsidiárias e dados empíricos, acarretar consequências empiricamente testáveis". Esquematicamente: Cientifica $\leftrightarrow$ Comprovável \& compativel com o conhecimento comum (científico). Por exemplo: o alegado poder de algumas pessoas de mover objetos com a força do pensamento é uma tese pseudocientífica, segundo Bunge, as razões para isso seriam: 1) que o fato nunca foi comprovado por observação ou experimento; (2) que o fato é incompatível com o princípio de conservação de energia. 


\section{O MÉTODO CIENTÍFICO COMO CRITÉRIO DE DEMARCAÇÃO}

Se existe um método científico, não seria ele um critério para demarcar a ciência e a não ciência? Parece-nos que sim. Contudo, muitos filósofos, desde a década de 1960, têm criticado a noção de método científico, alegando que se trata de um mito filosófico. Se entendermos o método científico como um método único, universal para todas as ciências, um conjunto de regras, um algoritmo que seja capaz de inventar hipóteses e resolver problemas parece que tal coisa não existe.

Contudo, existem defesas sofisticadas da existência de um método científico comum a todas as ciências. Entre os defensores da existência de um tal método estão, por exemplo, Barry Gower em Scientific Method: and historical and philosophical introduction, publicado em 1997, e Mário Bunge, em várias obras, entre as quais destaca-se La investigación científica, de $1989^{10}$.

Como dissemos acima, Mario Bunge é defensor do método científico há décadas. Sua visão é de que existe um método geral da ciência, e todas as ciências particulares devem obedecer. Porém, como ele mesmo afirma a respeito do método "[ele apenas] forma, mas não informa". Contudo, ele ressalta, cada ciência tem seu conjunto de métodos particulares adaptados ao objeto de estudo específico. Bunge chama esse conjunto de métodos de metódica que difere muito entre as ciências. As metódicas da matemática, da botânica e da biomedicina são muito distintas. Além disso, em cada subárea há diferenças, por exemplo, a metódica para se estudar o cérebro é, em grande parte, distinta da do pulmão.

Vejamos como Bunge resume as etapas do método científico geral em seu livro Epistemologia (1980, p. 25):

(1) Descobrimento do problema ou lacuna num conjunto de conhecimentos. Se o problema não estiver enunciado com clareza, passa-se à etapa seguinte; se o estiver, passa-se à subsequente.

(2) Colocação precisa do problema, dentro do possível em termos matemáticos, ainda que não necessariamente quantitativos. Ou ainda recolocação de um velho problema à luz de novos conhecimentos (empíricos ou teóricos, substantivos ou metodológicos).

(3) Procura de conhecimentos ou instrumentos relevantes ao problema (por ex., dados empíricos, teorias, aparelhos de medição, técnicas de cálculo ou de medição). Ou seja, exame do conhecimento para tentar resolver o problema.

(4) Tentativa de solução do problema com auxílio dos meios identificados. Se a tentativa resultar inútil, passa-se para a etapa seguinte; em caso contrário. À subsequente.

\footnotetext{
${ }^{10}$ Para maiores esclarecimentos acerca do método científico, ver Nola e Shankey (2007).
} 
(5) Invenção de novas ideias (hipóteses, teorias ou técnicas) ou produção de novos dados empíricos que prometam resolver o problema.

(6) Obtenção de uma solução (exata ou aproximada) do problema com auxílio do instrumental conceitual ou empírico disponível.

(7) Investigação das consequências da solução obtida. Em se tratando de uma teoria, procura de prognósticos que possam ser feitos com seu auxílio. Em se tratando de novos dados, exame das consequências que possam ter para as teorias relevantes.

(8) Prova (comprovação) da solução: confronto da solução com a totalidade das teorias e da informação empírica pertinente. Se o resultado é satisfatório a pesquisa e dada por concluída até novo aviso. Do contrário, passa-se para a etapa seguinte.

(9) Correção das hipóteses, teorias, procedimentos ou dados empregados na obtenção da solução incorreta. Esse é, naturalmente, o começo de um novo ciclo de investigação.

Contudo, a visão da existência do método científico que era aceita pela maioria dos filósofos da primeira metade do século XX foi posta em questão famosamente por dois filósofos que defenderam o pluralismo em relação ao método científico. O primeiro deles foi Thomas Samuel Kuhn com a famosa obra a Estrutura das revoluções científicas, de 1962/1975. Sustentou nessa obra que a ciência é estabelecida quando da emergência de um paradigma. O paradigma informa os cientistas de uma determinada comunidade quais são os problemas e o modo adequado de resolver os problemas ou quebra-cabeças (puzzles). Contudo, os paradigmas são históricos e igualmente o modo de se fazer ciência. Não há apenas várias ciências, mas há várias químicas, físicas, biologias que foram se sucedendo na história da ciência. Há ciências, há métodos. Muitos filósofos da ciência nas últimas décadas do século passado aceitaram os argumentos de Kuhn contra a existência de um método científico geral.

O segundo contestador é Paul Feyerabend (1924-1994) em sua obra Contra o método, de 1975/2007. Nas palavras de Feyerabend no início de seu famoso livro:

\footnotetext{
A ideia de conduzir os negócios da ciência com o auxílio de um método que encerre princípios firmes, imutáveis e incondicionalmente obrigatórios vê-se diante de considerável dificuldade quando posta em confronto com os resultados da pesquisa histórica. Verificamos, fazendo um confronto, que não há uma só regra, embora plausível e bem fundamentada na epistemologia, que deixe de ser violada em algum momento. Torna-se claro que as violações nas são eventos acidentais, não são o resultado de conhecimentos insuficientes ou de desatenção que poderia ter sido evitada. Percebemos, ao contrário, que as violações são necessárias para o progresso. (FEYERABEND, 2007, p. 29).
}

Segundo Feyerabend, o único procedimento que não atrapalha o desenvolvimento e o progresso científico é o "tudo vale”, o seu famoso anarquismo epistemológico. 


\section{O CRITÉRIO DE CIENTIFICIDADE POR MEIO DE VIRTUDES}

Nesse momento, proponho uma estratégia para diferenciar a ciência da pseudociência a partir das ideias de Thomas S. Kuhn. Essa estratégia não busca uma definição de ciência ou um critério único e simples para distinguir ciência de não ciência, nem se baseia em um suposto método científico universal ${ }^{11}$.

O cerne do que estamos propondo, à maneira de Thomas Kuhn, é estabelecer virtudes que podem nos auxiliar a distinguir quando uma determinada teoria é científica ou não. Em seu texto "Objetividade, juízo de valor e escolha teoria", de 1973, escrito a partir de uma conferência proferida na Furman University na Carolina do Sul (E.U.A), Kuhn tem como tema que a escolha entre teorias científicas não é algorítmica. Ele deseja defender-se da leitura relativista da escolha entre teorias de paradigma rivais que foi feita principalmente de seu capítulo 11 da Estrutura acerca da Resolução de revoluções. A escolha teórica seria apenas, segundo Lakatos, uma questão de "psicologia de massas". Nesse texto, Kuhn (1977, p. 385) sustenta que são cinco as características que tornam uma teoria científica uma boa teoria. São eles a exatidão, a consistência interna e externa, o longo alcance, a simplicidade e a fecundidade ${ }^{12}$. Porém, pesados e hierarquizados de modos diversos entre paradigmas.

Temos que deixar claro que um dos elementos de nossa proposta é que uma teoria pode ser mais científica do que outras, assim como faz Bunge (2006). Por exemplo, a teórica quântica é considerada exemplo típico de ciência. Apenas a título de exemplo, enquanto a economia pode ser colocada numa zona intermediária, a acupuntura, a homeopatia, a ufologia e a astrologia são exemplos típicos de pseudociência, pois possuem poucas virtudes ou falta alguma virtude importante ${ }^{13}$.

Estamos entendendo por virtude uma propriedade ou característica também de teorias, não apenas de ações humanas. Essa propriedade relacional é fruto de uma avaliação de um sujeito ou de uma comunidade em relação a uma teoria ou modelo. Os termos "virtude" e "valor" são tomados como sinônimos. Podemos distinguir as virtudes em sociais, cognitivas e pragmáticas. Um exemplo de virtude social é a liberdade. O que nos interessa para resolver o

\footnotetext{
${ }^{11}$ Existem muitos outros critérios de cientificidade a partir de virtudes ou valores, por exemplo, o baseado no ethos científico como o proposto pelo sociólogo Robert K. Merton (1942).

${ }^{12}$ Esse modo de conceber a escolha teórica foi desenvolvido posteriormente por McMullin (1996), Lacey (1999; 2008) e outros. Estamos neste texto aplicando a mesma solução para a escolha entre teorias como uma solução viável ao problema da demarcação.

${ }^{13} \mathrm{Nem}$ todos concordariam com tais alegações de pseudocientificidade dessas perspectivas, apenas como exemplo, o caso da homeopatia, uma defesa de sua cientificidade ou simpatia ver Chibeni (2002). Na mesma revista, o interessado pode achar vários artigos que defendem a cientificidade da homeopatia.
} 
problema da demarcação são as virtudes cognitivas e pragmáticas. As virtudes cognitivas e pragmáticas são características de teorias aceitáveis (LACEY, 1999, p. 45). As virtudes cognitivas são condutoras epistêmicas, isso é, indicam que a teoria é justificada, verdadeira ou parcialmente verdadeira. As virtudes pragmáticas são aquelas que promovem alguma vantagem prática, por exemplo, a simplicidade teórica.

Mas quais são as virtudes que tornariam uma teoria aceitável como científica? Elencaremos abaixo uma lista de virtudes que não pretende ser completa, pois até o momento não há tal lista. Essas virtudes estão disseminadas na literatura filosófica sobre o tema ${ }^{14}$.

As virtudes como critério de demarcação posto sumariamente é o seguinte: uma teoria ou modelo que contenha virtudes cognitivas e pragmáticas e que seja reconhecida (por indivíduo ou comunidade competente) pode ser qualificada como teoria cientificamente madura ou não.

Vejamos algumas dessas virtudes que fornecem critérios para a demarcação advinda de várias fontes teóricas:

1. Adequação empírica (as teorias científicas e suas predições dão conta do que é observável); (Bas van Fraassen) ${ }^{15}$.

2. Universalidade (as teorias científicas valem ou para o universo todo - as leis da física - ou para o contexto para as quais são elaboradas - as leis biológicas); (Aristóteles).

3. Objetividade (o objeto da pesquisa, os procedimentos e os resultados são públicos e qualquer cientista com as qualificações necessárias e o laboratório adequado pode refazer o experimento e replicar os resultados); (Karl Popper).

4. São abertas à crítica racional e não defendidas a todo custo contra as evidências empíricas contrárias; (Karl Popper).

5. As hipóteses, as leis e as teorias estão claramente elaboradas e de modo ideal matematizadas; (Mário Bunge).

6. As hipóteses são passíveis de contrastação empírica e fazem predições arriscadas. Elas podem ser verificadas (há apoio em evidências) e podem ser falseadas; (Mário Bunge).

\footnotetext{
${ }^{14}$ Além do texto de Kuhn já citado, ver McMullin, 1983 e 1996; Lacey, 1999, cap. 3, p.45-65; 2008, p. 84-86.

${ }^{15}$ Estamos apenas exemplificando autores que defenderam de modo bastante veemente essas virtudes em suas metaciências, pois há muitos outros que defenderam e defendem as mesmas virtudes tanto no passado como no presente como propriedades importantes das teorias científicas.
} 
7. A validez das teorias não está baseada na mera autoridade de seu proponente; (Mário Bunge).

8. As teorias são postas de lado a partir de em contrário e substituídas por teorias melhores. (Aristóteles, Tomás de Aquino).

9. A ciência progride no sentido que uma teoria estável demais é um indício de não ser científica; (Thomas Kuhn).

10. As teorias são coerentes internamente (logicamente) e coerentes externamente com outras teorias científicas; (Mário Bunge).

11. Há experimentação controlada e reprodutível; (Karl Popper).

12. Fecundidade: a teoria deve ser fonte de novas descobertas; (Thomas Kuhn).

Uma teoria que possui essas virtudes em algum grau torna-as aceitáveis como teorias científicas. A aplicação desse critério é semelhante ao diagnóstico médico e pode sempre ser revisto, ampliado e não aplicado quando temos boas razões para fazê-lo. Portanto, uma teoria que não possui uma determinada virtude não implica que estejamos imediatamente diante de um caso de pseudociência, bem como ter algumas virtudes não torna a teoria imediatamente ciência. Esse modo de estabelecer qual é uma teoria científica é vago e impreciso. Partilhamos a visão aristotélica e kuhniana de que sobre certos assuntos não podemos exigir maior exatidão dada à natureza do objeto. Parece não ser igualmente possível, por enquanto, estabelecer com precisão os níveis de cientificidade.

Outro modo de colocar os critérios de cientificidade é não focando nas virtudes das teorias, mas no oposto, nos vícios ou antivalores. Seguimos aqui a lista elaborada por Seven Ove Hansson (2015) a partir de várias fontes:

1. Crença na autoridade: devemos aceitar uma teoria porque alguém com habilidades especiais a defende e devemos segui-lo na aceitação dessa teoria.

2. Experiências não repetíveis: experiências que não podem ser refeitas por outras pessoas em condições similares.

3. Teoria não submetida a teste: uma teoria com capacidade de ser testada, mas não foi submetida a testes.

4. Desconsiderar algo que desabone a teoria: observações, experimentos, dados que falsifiquem a teoria são negligenciadas.

5. Teste tautológico: o teste apenas confirma a teoria, não permite refutá-la.

6. Perda teórica: uma teoria melhor é abandonada em favor de uma teoria pior, a saber, explica menos coisa que a anterior. 
Em suma, parece-nos que a pergunta correta no caso da demarcação por meio de virtudes ou vícios, ao modo de Goodman em seu texto Quando há arte? (2007), não é o que é a ciência, mas quando há ciência.

\section{CONSIDERAÇÕES FINAIS}

Vimos que o problema da demarcação é um sério problema, não apenas com repercussões teóricas, mas consequências práticas. Igualmente, há várias soluções, modelos ou estratégias para enfrentar o problema da demarcação. De modo sumário, vimos três perspectivas: a primeira é buscar uma definição de ciência e assim ter critérios de discriminação entre ciência e não ciência. Outro modo é estabelecer uma metodologia própria da ciência que a distinga de outras práticas, o chamado método científico. Por fim, outro modo, baseado em Thomas Kuhn, é por meio de virtudes que possibilitem a distinção entre o que é ciência e não ciência.

Compartilhamos, porém timidamente, o otimismo de Seven Oven Hansson (2015), mesmo que não temos uma teoria metacientífica da demarcação precisa o suficiente para resolver todos os casos envolvendo o discernimento de ciência e não ciência, na maioria dos casos, há um consenso nas comunidades científicas sobre quais teorias são científicas e aquelas que não são. Assim, são consideradas como exemplos de não ciências: o criacionismo, a astrologia, a homeopatia, a ufologia, a teoria dos antigos astronautas, a teorias da negação do holocausto, a negação da mudança climática, a fotografia kirlian ou a kirliangrafia, a radiestesia, o catastrofismo velikovskiano. Todavia, na sociedade, na mídia e entre os políticos há uma grande confusão, como exemplos: a recusa das vacinas como conspiração do Estado; a homeopatia como terapia nos hospitais públicos; a campanha de políticos e religiosos para estabelecer o ensino do criacionismo nas escolas.

\section{REFERÊNCIAS}

BUNGE, Mario. Dicionário de filosofia. São Paulo: Perspectiva, 2006.

BUNGE, Mario. Epistemologia: curso de atualização. São Paulo: EDUSP, 1980.

BUNGE, Mario. La investigación científica. Barcelona: Ariel, 1989.

CHIBENI Silvio Seno. A homeopatia como ciência: uma análise filosófica. Revista de Homeopatia. Associação Médica de Homeopatia Brasileira. n. 4, p. 89-96, 2002. 
CUAPANI, Alberto. Filosofia da ciência. Florianópolis: Filosofia/EAD/UFSC, 2009.

DUPRÉ, John. The disorder of things: metaphysical foundations of the disunity of science. Harvard: Harvard University Press, 1993.

FEYERABEND, Paul. Contra o método [1975]. São Paulo: UNESP, 2007.

FEYERABEND, Paul. A ciência em uma sociedade livre. São Paulo: UNESP, 2011.

GHINS, Michel. Uma introdução à metafísica da natureza: representação, realismo e leis científicas. Curitiba: UFPR, 2013.

GOODMAN, Nelson. Quando há arte? In: D’OREY Carmo (Org.). O que é arte? A perspectiva analítica. Lisboa: Dinalivros, 2007.

GROVER, Barry. Scientific Method: and historical and philosophical introduction. London: Routledge, 1996.

HANSSON, Seven Oven. Pseudo-science and Science. Stanford Encyclopedia of Philosophy. Disponível em: http://plato.stanford.edu/entries/pseudo-science/.. Acesso em: 27 jun. 2015.

KUHN, Thomas Samuel. A tensão essencial. Lisboa: Edições 70, 1977.

KUHN, Thomas Samuel. A estrutura das revoluções científicas. São Paulo: Perspectiva, 1975.

KUHN, Thomas Samuel. "Objetividade, juízo de valor e escolha teórica”. In: Tensão essencial. Lisboa: Edições 70, 1977

LACEY, Hugh. Is Science value free? Values and scientific understanding. London: Routledge, 1999.

LACEY, Hugh. Valores e atividade científica 1. São Paulo: Ed. 34, 2008.

LAKATOS, Imre. The Methodology of Scientific Research Programmes: Volume 1:

Philosophical Papers (Philosophical Papers Volume I). Cambridge: Cambridge University Press, 1980.

LATOUR, Bruno; WOOLGAR, Steve. A vida de laboratório: a produção dos fatos científicos. Tradução de Angela R. Vianna. Rio de Janeiro: Relume-Dumará, 1997.

McMULLIN, E. Values in Science. In: ASQUITH, P. e NICLES, T. (Org.). East Lansing: Philosophy of Science Association, 1983, p. 3-28.

McMULLIN, E. Values in science. In: NEWTON-SMITH, W. (Org.). A companion to the philosophy of science. Oxford: Balckwell Publishers, 1996, p. 550-62. 
MELLO, A. da Silva. Ilusões da psicanálise. São Paulo: Civilização Brasileira, 1967.

MERTON Robert K. Science and Technology in a Democratic Order. Journal of Legal and Political Sociology, 1, p. 115-126, 1942.

NOLAN, Robert e SANKEY, Howard. Theories of scientific method: an introduction. Stocksfield: Acumen, 2007.

ONFRAY, M. Freud: el crepusculo de un ídolo. Madrid: Taurus, 2011.

PERELSON, S. O livro negro da psicanálise: viver e pensar melhor sem Freud. São Paulo: Civilização Brasileira, 2005.

PIGLIUCCI, Massimo; BOUDRY, Maarten (Ed.). Philosophy of pseudo-science: reconsidering problem of demarcation. University of Chicago Press, 2013.

PINCKNEY, E. Psicanálise: a mistificação do século. São Paulo: EDIGRAF, 1970.

POPPER, Karl, R. Conjecturas e refutações. 4. ed. Brasília: UNB, 1972.

POPPER, Karl, R. Reply to my critics. In: SCHILPP P. A. The Philosophy of Karl Popper. The Library of Living Philosophers, vol xiv, book ii. La Salle: Open Court. p. 961-1197.

ROUDINESCO, E. Freud: mas por que tanto ódio? Rio de Janeiro: Zahar, 2011. SANTAMARÍA, C.; FUMERO, A. Psicanálisis ¡vaya timo! Pamplona: Laetoli, 2008. 